\title{
In vitro and in vivo susceptibility of Salmonella spp. isolated from broiler chickens
}

\author{
Naser Ranjbar Malidareh • Sobhan Firouzi • \\ Neda Ranjbar Malidareh • Hassan Habibi
}

Received: 12 January 2012 / Accepted: 30 May 2012 /Published online: 15 June 2012

(C) The Author(s) 2012. This article is published with open access at Springerlink.com

\begin{abstract}
Salmonellosis is the most important zoonotic disease, causing diarrhea and systemic infections. Due to poor management in antibiotic consumption, microbial resistance has increased in the treatment of zoonotic diseases. This study was conducted to evaluate the antimicrobial susceptibility of Salmonella spp. isolated from day-old broiler chickens which were referred to a private laboratory in Mazandaran - a province in the north of Iran-from 2008 to 2010. After harvesting the samples from the yolk sac, liver, and intestine of chickens, intestinal samples were transferred to selenite $\mathrm{F}$ and then incubated at $43{ }^{\circ} \mathrm{C}$ for 12-16 h. A loopful from selenite $\mathrm{F}$ and samples of liver and yolk sac were streaked on XLD and S.S agars. After incubation, the suspected colonies were inoculated into TSI agar for biochemical confirmation. The disk diffusion method on Muller Hinton agar was used to determine the susceptibility to antimicrobial agents. Because of the predominant use of enrofloxacin, sulfadiazine + trimethoprim, and flumequine for controlling Salmonella and Escherichia coli infections in the first week of broilers brooding in Iran, these three
\end{abstract}

\author{
N. Ranjbar Malidareh \\ Clinician of Veterinary Diagnostic Laboratory, \\ Babol, Iran \\ e-mail: naser.ranjbar@gmail.com \\ S. Firouzi $(\bowtie) \cdot$ H. Habibi \\ Avian Diseases Research Center, School of Veterinary Medicine, \\ Shiraz University, \\ Shiraz, Iran \\ e-mail: s.firouzi65@gmail.com \\ H. Habibi \\ e-mail: hassan1382h@yahoo.com \\ N. Ranjbar Malidareh \\ Expert of Veterinary Diagnostic Laboratory, \\ Babol, Iran
}

antibiotics were used in the in vivo study. From day 2 and continuing for 4 days, antibiotics were administrated in water, and after 10 days, samples from the liver, heart, and intestine were taken for isolation of Salmonella. In antimicrobial resistant tests, the most susceptible antibiotics were chloramphenicol, cefotaxime, and sulfadiazine + trimethoprim. The antimicrobial resistance to enrofloxacin, flumequine, colistin, and neomycin were 6.6, 11.6, 21.6, and $33.3 \%$, respectively. The results showed that 12 parties of broiler chickens were infected with paratyphoid salmonellae and the in vivo study showed that enrofloxacin and sulfadiazine + trimethoprim had the best and the weakest performance, respectively.

Keywords Salmonella $\cdot$ Antimicrobial resistance $\cdot$ In vivo . Broiler chicken · Iran

\section{Introduction}

Salmonella spp. is among the most important food-borne pathogens in the world. Poultry and poultry products are usually incriminated in human salmonellosis outbreaks. Between 1997 and 1998, 37,842 cases of human salmonellosis were reported to the Centers for Disease Control and Prevention. The estimated number of human Salmonella infections in the USA exceeds 1.4 million annually (Mead et al. 1999).

Salmonella spp. are among the major bacterial pathogens of poultry worldwide, and most Salmonella infections in human result from the ingestion of contaminated poultry (Carli et al. 2001). During the last decade, there has been an alarming increase in the appearance of antibiotic-resistant bacteria as a result of poor management in antibiotic consumption. The administration of antimicrobial agents in 
chickens creates selection pressure that favors the survival of antibiotic-resistant pathogens. Resistance of Salmonella to commonly used antimicrobials is increasing, both in the veterinary field and the public health sector and has emerged as a global challenge (Molla et al. 2003). Recent studies from different countries reveal that Salmonella serotypes isolated from foods of animal origin have multidrug resistance profiles (Prats et al. 2000; Winokur et al. 2000; Holt et al. 2007). The aim of the present study was to determine the antimicrobial susceptibility of Salmonella spp. isolated from day-old broiler chickens. The efficacy of some antibiotics that are commonly used in the first week of brooding was also investigated in the experimental study.

\section{Materials and methods}

Samples collection A cross-sectional study was conducted by analyzing samples of day-old broiler chickens that had referred to a private laboratory in Mazandaran, a province in the north of Iran, between 2008 and 2010. Chickens were euthanized and samples from the liver, yolk sac, and intestine were collected.

Isolation Samples which were derived from the intestinal tract were initially transferred into selenite $\mathrm{F}$ with sterile swab and incubated at $43{ }^{\circ} \mathrm{C}$ for $12-16 \mathrm{~h}$. Then a loopful from selective enriched media was streaked onto plates of Salmonella-Shigella (S.S) and xylose lysine deoxycholate (XLD) agars. Loop samples of the liver and yolk sac were taken and transferred directly to plates of S.S agar and XLD agar for further incubation at $37^{\circ} \mathrm{C}$ for $24 \mathrm{~h}$. Tissue samples ordinarily contain relatively few competing organisms and are often transferred directly to plates of both selective and nonselective agar media, without broth enrichment (Gast 2008). Up to three suspected colonies with typical Salmonella morphology were confirmed biochemically by inoculating into triple sugar iron agar.

Antimicrobial susceptibility tests The disk diffusion method was performed to determine susceptibility of the Salmonella isolates based on the NCCLS 1996 protocol (National Committee for Clinical Laboratory Standards; Table 1). The bacterial suspension turbidity was adjusted to McFarland standard number 0.5 in Mueller Hinton broth (Merck) and cultured fluently over the entire surface of Muller Hinton agar with sterile cotton swab. Commercial antibiotic disks containing single concentrations of each antibiotic were then placed onto the inoculated plate surface. The zone of inhibition of growth around each disk after overnight incubation at $37{ }^{\circ} \mathrm{C}$ was measured in millimeters. The zone diameter was interpreted using a zone size interpretation chart (Lorian 1996). The antimicrobial agents tested and the corresponding concentrations were as follows: chloramphenicol $30 \mu \mathrm{g}$, cefotaxime $5 \mu \mathrm{g}$, flumequine $30 \mu \mathrm{g}$, colistin $10 \mu \mathrm{g}$, neomycin $30 \mu \mathrm{g}$, sulfadiazine + trimethoprim (sultrim) $15 \mu \mathrm{g}$, and enrofloxacin $5 \mu \mathrm{g}$.

In vivo study Among poultry producers, using such antibiotics during the first week of broiler management for the prevention and control of Salmonella and Escherichia coli infections is a common tradition. In the present study, enrofloxacin, sultrim, and flumequine were used in the in vivo study because of the predominant use of these three antibiotics in this age. After isolating Salmonella from the chickens, 40day-old broiler chickens were purchased from related hatcheries. Chicks were randomly divided into four groups of 10 chicks per group, and antibiotics were administrated in water from day 2 for 4 days. After 10 days, samples from the liver, heart, and intestine were taken for isolation of Salmonella.

\section{Results}

Out of the 730 chickens from 43 broiler breeder farms between 2008 and 2010, 60 chicks were positive for Salmonella. This prevalence of $8.2 \%$ was for 12 broiler breeder farms. All 60 chicken isolates were susceptible $(100 \%)$ to chloramphenicol, cefotaxime, and sultrim. Resistance to enrofloxacin, flumequine, colistin, and neomycin were evident at $6.66,11.66,21.66$, and $33.33 \%$, respectively. With regard to the in vivo study, after random sampling from the liver, heart, and intestine of chicken in each group at day 15 , the following results were obtained with respect to isolating Salmonella spp.:

- Enrofloxacin treatment groups: growth of Salmonella colony was negative.

- Flumequine treatment groups: the rate of Salmonella colonies that grew on plates was low.

Table 1 Antimicrobial susceptibility of Salmonella spp. isolated from day-old broiler chicken

\begin{tabular}{lccl}
\hline Antimicrobial & \multicolumn{2}{l}{ Number (percent) } \\
\cline { 2 - 4 } & Resistant & Intermediate & Sensitive \\
\hline Chloramphenicol & $0(0)$ & $2(3.3)$ & $58(96.7)$ \\
Cefotaxime & $0(0)$ & $1(1.66)$ & $59(98.33)$ \\
Colistin & $13(21.66)$ & $5(8.33)$ & $42(70)$ \\
Enrofloxacin & $4(6.66)$ & $3(5)$ & $53(88.33)$ \\
Sultrim & $0(0)$ & $2(3.3)$ & $58(96.7)$ \\
Neomycin & $20(33.33)$ & $12(20)$ & $28(46.66)$ \\
Flumecoine & $7(11.66)$ & $3(5)$ & $50(83.33)$ \\
\hline
\end{tabular}


- Sultrim treatment groups: growth of Salmonella colonies was more than the flumequine groups.

\section{Discussion}

Our results can be compared to the findings reported by Yildirim et al. (2011), where 90 and $97 \%$ of isolated Salmonella from chicken carcasses were susceptible to chloramphenicol and cefotaxime, respectively, while just $44 \%$ was susceptible to neomycin. These susceptibility rates are in agreement with those observed in the Zahraei Salehi et al. (2005) study. They isolated Salmonella from the intestine and liver of broiler chickens, and the results of the antimicrobial tests showed that all of the isolated Salmonella were susceptible to chloramphenicol, cefotaxime, and enrofloxacin, while $79.3 \%$ of samples were susceptible to flumequine and trimethoprim. In one investigation performed in Portugal, poultry samples were frequently contaminated with Salmonella $(60 \%)$. In antimicrobial resistance tests, susceptibility to cefotaxime, chloramphenicol, and sultrim were 100, 97, and $97 \%$, respectively (Antunes et al. 2003). Among seven antimicrobial tests performed in Thailand, susceptibility of Salmonella isolated from chicken carcasses to chloramphenicol and sultrim was 100 and $98 \%$, respectively (Dahal et al. 2008). All of these results are in agreement with the present study.

Usage of antibiotics in poultry is for three purposes including: therapy, prevention, and growth promotion. The classes used include: $\beta$-lactams (penicillins and cephalosporins), sulfonamides $\beta$-lactams with and without trimethoprim, tetracyclines, macrolides, lincosamides and streptogramins, and quinolones (including fluoroquinolones $\beta$-lactams), which have a variety of therapeutic and preventive applications in food animals and are the same classes as those used in human therapy.

Much of the evidence relating to the potential for transfer of a resistance problem from animals to man comes from a consideration of the epidemiology of zoonoses, mainly Salmonella and Campylobacter infection (Chiu et al. 2002). The hypothesis is that the food chain is the main means of transmission. This hypothesis is intuitively attractive, and there can be no doubt of the existence of a hazard, but neither of these consideration means that the hypothesis is correct or of universal significance.

For example, enrofloxacin was not introduced for animal therapy until 1995, by which time $21 \%$ of human isolates in one Pennsylvania study were resistant to ciprofloxacin, none having been resistant between 1982 and 1992, and by 2001, $40 \%$ of human isolates were resistant to fluoroquinolones in this study (Nachamkin et al. 2002).

Salmonella typhimurium and Salmonella infantis are serotypes frequently isolated from food-producing animals and food poisoning cases in Japan. S. typhimurium DT104 and 104B were isolated from feces and diagnostic submissions mainly from cattle; some were also isolated from diagnostic submissions from swine. With the antibiotic resistance genes integrated in the chromosome, most DT104 isolates show MDR to five drugs, commonly referred to as resistance (R)-type ACSSuT (Threlfall et al. 1994). However, $S$. infantis was frequently isolated from patients suffering from food-borne illness and presents a significant public health concern related to poultry possessing strains with some resistance determinants (Esaki et al. 2003).

\section{Conclusion}

Efforts are crucial to reduce the prevalence of resistant Salmonella in poultry, including the adoption of guidelines for the prudent use of antimicrobial agents in animals used for food and a reduction in the number of pathogens present on farms. The target organisms must be known or shown to be susceptible, and adequate concentrations of antibiotics must be shown to reach the target. We believe that efforts should be concentrated instead on minimizing the transmission of all food-borne pathogens regardless of their antibiotic susceptibility, by insistence on good hygiene practices on farms, in abattoirs, during distribution and marketing of food, in food preparation, and, finally, by the consumer.

Acknowledgments We acknowledge the Day Veterinary Diagnostic Laboratory (Fax +981112236386 Babol, Iran) for providing facilities and funding the project.

Open Access This article is distributed under the terms of the Creative Commons Attribution License which permits any use, distribution, and reproduction in any medium, provided the original author(s) and the source are credited.

\section{References}

Antunes P, Re'u C, Carlos Sousa J, Peixe L, Pestana N (2003) Incidence of Salmonella from poultry products and their susceptibility to antimicrobial agents. Int J Food Microbiol 8:97-103

Carli KT, Unal CB, Caner V, Eyigor A (2001) Detection of Salmonellae in chicken feces by a combination of tetrathinate broth enrichment, capillary PCR, and capillary gel electrophoresis. J Clin Microbiol 39:1871-1876

Chiu CH, Wu TL, Su LH et al (2002) The emergence in Taiwan of fluoroquinolone resistance in Salmonella enterica serotype choleraesuis. N Engl J Med 346:413-419

Dahal N, Ellerbroek L, Poosaran N (2008) Prevalence and antimicrobial resistance of Salmonella in imported chicken carcasses in Bhutan. Proceedings, the 15th Congress of FAVA

Esaki H, Morioka A, Ishihara K, Kojima A, Shiroki S, Tamura Y, Takahashi T (2003) Antimicrobial susceptibility of Salmonella isolated from cattle, swine and poultry (2001-2002): report from the Japanese Veterinary Antimicrobial Resistance Monitoring Program. J Antimicrob Chemother 53(2):266-270 
Gast RK (2008) Paratyphoid infections. In: Saif YM, Fadly AM, Glisson JR, McDougald LR, Nolan LK, Swayne DE (eds) Diseases of poultry, 12th edn. Iowa State University Press, Ames, pp 636-665

Holt KE, Thomson NR, Wain J, Phan MD, Nair S, Hasan R et al (2007) Multidrug-resistant Salmonella enteric serovars paratyphi A harbors IncHI1 plasmids similar to those found in serovar typhi. J Bacteriol 189:4257-4264

Lorian V (1996) Antibiotics in laboratory medicine, 4th edn. Williams \& Wilkins, Baltimore

Mead PS, Slutsker L, Dietz V, McCaig LR, Bresee JS, Shapiro C, Griffin PM, Tauxe RV (1999) Food-related illness and death in the United States. Emerg Infect Dis 5:607-625

Molla B, Mesfin A, Alemayehu D (2003) Multiple antimicrobialresistant Salmonella serotypes isolated from chicken carcasses and giblets in Debre Zeit and Addis Ababa, Ethiopia. Ethiop J Health Dev 17:131-149

Nachamkin I, Ung H, Li M (2002) Increasing fluoroquinolones resistance in Campylobacter jejuni, Pennsylvania, USA, 1982-2001. Emerg Infect Dis 8:1501-1503
Prats G, Mirelis B, Lovet T, Munoz C, Miro E, Navarro F (2000) Antibiotic resistance trends in enteropathogenic bacteria isolated in 1985-1987 and 1995-1998 in Barcelona. Antimicrob Agents Chemother 44:1140-1145

Threlfall EJ, Frost JA, Ward LR et al (1994) Epidemic in cattle and humans of Salmonella typhimurium DT 104 with chromosomally integrated multiple drug resistance. Vet Rec 134:577

Winokur PL, Brueggemann A, DeSalvo DL, Hoffmann L, Apley MD, Uhlenhopp EK et al (2000) Animal and human multidrugresistant, cephalosporin-resistant Salmonella isolates expressing a plasmid-mediated CMY-2 AmpCßetalactamase. Antimicrob Agents Chemother 44(10):2777-2783

Yildirim Y, Gonulalan Z, Pamuk S, Ertas N (2011) Incidence and antibiotic resistance of Salmonella spp. on raw chicken carcasses. Food Res Int 44:725-728

Zahraei Salehi T, Mahzounieh M, Saeedzadeh A (2005) The isolation of antibiotic-resistant Salmonella from intestine and liver of poultry in Shiraz Province of Iran. Int J Poult Sci 4 (5):320-322 